\title{
Tetrazolium/Formazan Test as an Efficient Method to Determine Fungal Chitosan Antimicrobial Activity
}

\author{
Shaaban H. Moussa, ${ }^{1,2}$ Ahmed A. Tayel, ${ }^{1}$ Ahmed A. Al-Hassan, ${ }^{3}$ and A. Farouk ${ }^{4}$ \\ ${ }^{1}$ Genetic Engineering and Biotechnology Research Institute, Minoufiya University, El-Sadat City, P.O. Box 79/22857, Egypt \\ ${ }^{2}$ The Promising Research Center in Biological Control and Agricultural Information, the University of Qassim, P.O. Box 6622, \\ Buraydah 51452, Saudi Arabia \\ ${ }^{3}$ Department of Food Science \& Human Nutrition, College of Agriculture \& Veterinary Medicine, Qassim University, P.O. Box 6622, \\ Buraydah 51452, Saudi Arabia \\ ${ }^{4}$ National Research Center, Textile Division, Textile Chemistry and Technology, Department of Preparation and \\ Finishing of Cellulosic Fibers, Tahrir Street, Dokki, P.O. Box 12622, Giza, Egypt
}

Correspondence should be addressed to Shaaban H. Moussa; shaus2008@yahoo.com

Received 8 March 2013; Revised 13 May 2013; Accepted 13 May 2013

Academic Editor: Zia U. Khan

Copyright (C) 2013 Shaaban H. Moussa et al. This is an open access article distributed under the Creative Commons Attribution License, which permits unrestricted use, distribution, and reproduction in any medium, provided the original work is properly cited.

Fungal chitosan was extracted from Aspergillus niger mycelia. The produced chitosan was characterized with deacetylation degree of $89.2 \%$, a molecular weight of $2.4 \times 10^{4} \mathrm{Da}$, and $96.0 \%$ solubility in $1 \%$ acetic acid solution. The antibacterial activity of fungal chitosan was evaluated against two foodborne pathogens, that is, Salmonella typhimurium and Staphylococcus aureus, using the established antibacterial assays, for example, zone of growth inhibition and agar plat count tests, and using 2,3,5,-triphenyltetrazolium chloride (TTC) as chromogenic marker for qualitative and quantitative determining of antibacterial potentiality. The TTC $(0.5 \% \mathrm{w} / \mathrm{v}) \mathrm{was}$ added, at concentration of $10 \%$, to cultured broth, containing chitosan with different concentrations then the formed formazan was separated. The formation of red formazan could be considered as a qualitative indication for antibacterial activity, whereas the measurement of color intensity for the resuspended red formazan, using spectrophotometer at $480 \mathrm{~nm}$, provided a quantitative evidence for the strength of the used antibacterial agent. Regarding the rapidity, technical simplicity, and cost-effectiveness, TTC assay could be recommended as an efficient alternative method for qualitative and quantitative determination of chitosan antibacterial activity and could be suggested for general evaluation of antibacterial agents.

\section{Introduction}

Chitosan is a cationic polysaccharide consisted of many monosaccharide units of $\beta$ - $(1,4)$ linked 2-amino-2-deoxy-D-glucopyranose. The innocuous biodegradable and bioeffective nature of chitosan recommends its use in many fields of biotechnology, food industry, cosmetology, agriculture, and phar-macology [1-3]. Chitosan can be extracted from the cell wall of fungi, particularly zygomycetes. The production of chitosan from fungal cell walls has many advantages such as independence of seasonal factor and wide-scale production. The extraction process is more simple and cheap resulting in a reduction in time and cost required for production [4].

The antimicrobial materials are widely used in industry, community, and private settings to prevent microbial infection and contamination. To obtain biocidal effect without releasing biocides into the environment, natural antimicrobials, like chitosan, are highly recommended to be applied. The antimicrobial activity of chitosan is a hot research topic and there are several articles dealing with it and its derivatives [2, 3, 5-7]. Moreover, chitosan has numerous advantages over other chemical disinfectants since it possesses a stronger antimicrobial activity, a broader range of activity, a higher antibacterial activity even at low concentrations, and a lower toxicity towards mammalian cells $[8,9]$.

Technological applications of fungal chitosan, as a natural antimicrobial agent, require a new method of detection. The agar diffusion method is the most frequently used $[10,11]$ and has been standardized as an official test method for detecting 


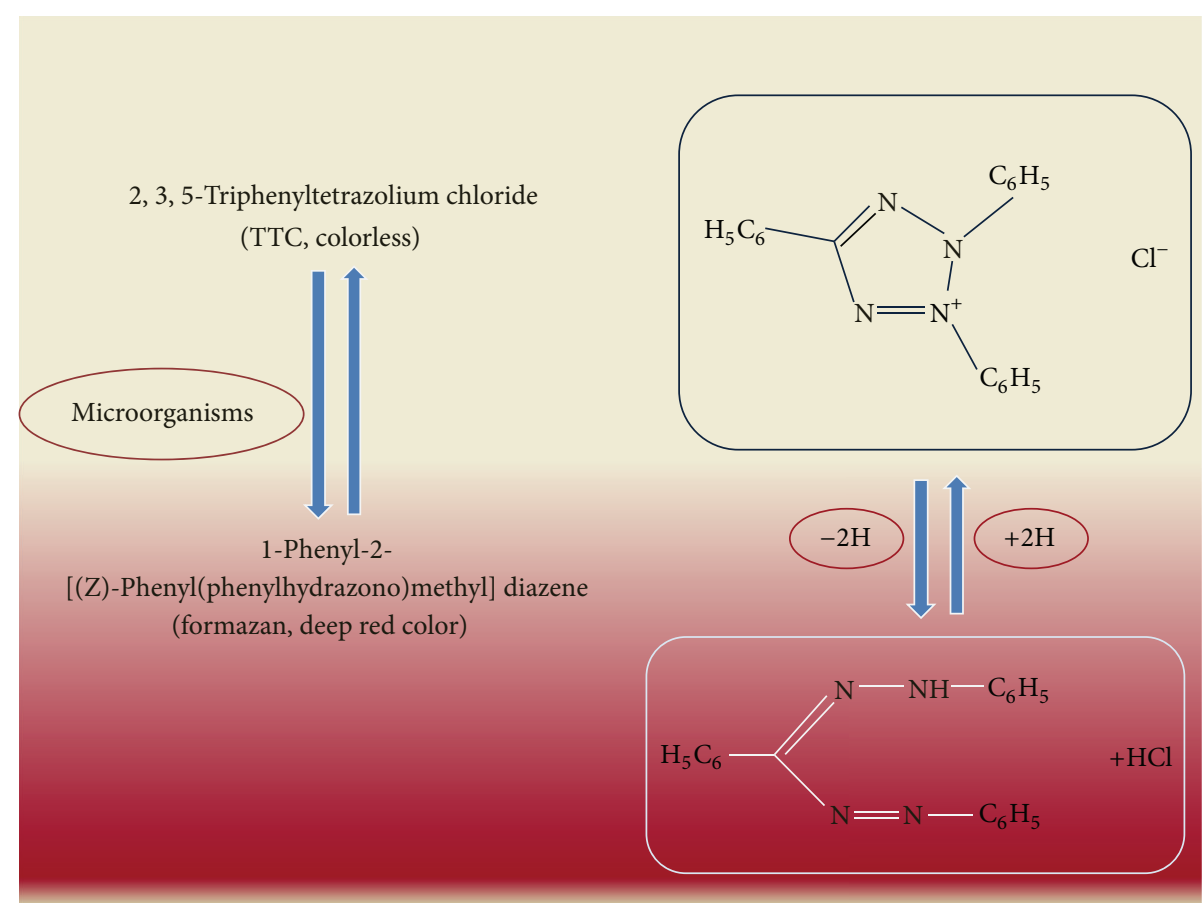

Figure 1: The tetrazolium-formazan biotransformation system. Adopated from Thom et al., 1993 [25].

bacteriostatic activity of natural antimicrobial agents. This test is limited for the detection of antimicrobial agents that are easily diffusible in agar. More direct methods were reported, such as the total count agar method; this method is also considered as time-consuming (18-24 h), particularly with microorganisms such as tuberculosis bacteria, which grow very slowly in the culture dish. Moreover, these methods require a large number of bacteria $\left(\sim 1.5 \times 10^{8}\right.$ cell $\left./ \mathrm{mL}\right)[12,13]$. Molecular methods for the determination of antimicrobial activity of natural compound, like chitosan, are available. However, the equipment and specialized skills required to perform such methods make them an impractical option, especially in developing countries $[14,15]$.

The Tetrazolium/formazan couple is a special redox system acting as proton acceptor or oxidant (Figure 1); this system is now widely applied in different branches of the biological science for example, medicine, pharmacology, immunology, and botany, but especially in biochemistry and histochemistry.

In the presence of bacteria, TTC is reduced to red formazan which is directly proportional to the viable active cells. Therefore, the TTC test method is considered as a comparatively fast method for evaluating the antibacterial activity of antimicrobial agents. In TTC assay, less than $12 \mathrm{~h}$ was required to attain susceptibility results and fewer bacterial counts are required.

The purpose of the current work was to evaluate the possibility of using the TTC method as quantitative and qualitative method for detecting the antibacterial activity of fungal chitosan.

\section{Materials and Methods}

The used chemicals and reagents in the current study were analytical grade and, unless other sources were mentioned, obtained from Sigma chemicals Co. (ST. Louis, MO, USA).

\subsection{Production of Fungal Chitosan. Aspergillus niger ATCC} 9642 was used for the production of chitosan in Potato Dextrose Broth (PDB; Merck, Darmstadt, Germany) at $28^{\circ} \mathrm{C}$ for $72 \mathrm{~h}$ under shake incubation condition. Chitosan extraction from mycelial biomass was performed as previously described $[6,8]$. Briefly, mycelial growth was harvested by centrifugation, washed twice with distilled water, and then homogenized with $1 \mathrm{M} \mathrm{NaOH}$ at $100^{\circ} \mathrm{C}$ for $1 \mathrm{~h}$. The alkali insoluble fraction was separated, washed, and neutralized with $5 \%$ acetic acid.

2.2. Characterization of Produced Chitosan. The physicochemical characteristics of the produced chitosan was determined according to the Association of Official Analytical Chemists (AOAC) [16] (viscosity, color, and solubility), whereas molecular weight was determined by gel permeation chromatography (GPC) using refractive index detector (PN1000, Postnova Analytics, Eresing, Germany). The method of Davies and Hayes [17] was applied to determine the degree of deacetylation of produced chitosan.

\subsection{Microbial Strains. Staphylococcus aureus ATCC-12599} and Salmonella enterica subsp. enterica serovar Typhimurium ATCC-23852 (deposited as Salmonella typhimurium) were examined for their susceptibility and sensitivity toward the 
treatment with produced chitosan. Bacterial strains were grown in nutrient broth $(\mathrm{NB})$ and maintained on nutrient agar (NA) media at $37^{\circ} \mathrm{C}$. Inoculums for the assays were prepared by diluting scraped cell mass in $0.85 \% \mathrm{NaCl}$ solution and counting using Haemocytometer, cells number was then adjusted to $10^{5}$ cell $/ \mathrm{mL}$ by dilution with saline solution.

\subsection{Evaluation of Antibacterial Activity of Chitosan. Two sets} of antibacterial evaluation methods were applied; the first was the Tetrazolium/formazan test (TTC) which was evaluated as a qualitative and quantitative antibacterial test method. The second set contained the standard methods, that is, zone of inhibition measurement and agar plate count, and was used for comparison of the TTC accuracy.

The chitosan dissolving solution, that is, $1 \%$ acetic acid, was used as negative control in all experiments.

\subsection{Tetrazolium/Formazan Test (TTC)}

2.5.1. TTC Preparation. TTC powder was dissolved in sterile distilled water at a concentration of $5 \mathrm{mg} / \mathrm{mL}$ at room temperature then filtered through $0.22 \mu \mathrm{m}$ Whatman filter paper and stored at $-20^{\circ} \mathrm{C}$ until used.

2.5.2. Susceptibility Test Using TTC. In the presence of bacteria, TTC is reduced to red formazan. The red formazan obtained indicates the activity and viability of the cells [21]. To do this test, $100 \mu \mathrm{L}$ from gradual concentrations of dissolved chitosan in $1 \%$ acetic acid, that is, $0,0.1,0.2,0.3$, 0.4 , and $0.5 \%$, was poured in $40 \mathrm{~mL}$ nutrient broth medium containing $20 \mu \mathrm{L}$ of $10^{8}$ cell $/ \mathrm{mL}$ challenge microorganisms (S. typhimurium and S. aureus). Chitosan-free solution was used as the blank control. All flasks were incubated with shaking at $37^{\circ} \mathrm{C}$ at $200 \times \mathrm{g}$ for $3 \mathrm{~h}$; then $1 \mathrm{~mL}$ from each flask containing the treated and the control cultures was added to sterilized test tubes containing $100 \mu \mathrm{L}$ TTC solution $(0.5 \% \mathrm{w} / \mathrm{v})$. All tubes were incubated at $37^{\circ} \mathrm{C}$ for $20 \mathrm{~min}$. The resulted formazan was centrifuged at $4000 \times \mathrm{g}$ for $3 \mathrm{~min}$. followed by decantation of the supernatants. The pellets obtained were resuspended and centrifuged again in ethanol $50 \%$. The red formazan solution obtained at the end which indicates the activity and viability of the cells was measured by spectrophotometer at $480 \mathrm{~nm}$.

\subsection{Standard Method}

2.6.1. Zone of Inhibition Test. The zone of growth inhibition test was carried out with a modified agar diffusion assay. Whatman papers No. 4 were cut into $6 \mathrm{~mm}$ diameter discs and sterilized by autoclaving; each disc was loaded with $50 \mu \mathrm{L}$ from chitosan $1 \%$. Discs were then placed on nutrient agar in Petri dishes which had been seeded with $20 \mu \mathrm{L}$ of bacterial cell suspensions. The Petri dishes were examined for zone of inhibition after $24 \mathrm{~h}$ incubation at $37^{\circ} \mathrm{C}$. The area of the whole zone was calculated and then subtracted from the film disc area, and the difference in area was reported as the "zone of inhibition."
2.6.2. Agar Plate Count Test [13]. As a quantitative method for determining the degree of chitosan antibacterial activity, bacterial count was determined after growth in nutrient Broth (NB) containing gradual concentrations of dissolved chitosan in $1 \%$ acetic acid, that is, $0,0.1,0.2,0.30 .4$, and $0.5 \%$, using serial dilutions technique. $100 \mu \mathrm{L}$ of bacterial cell suspensions from diluted cultures, after incubation for $3 \mathrm{~h}$ at $37^{\circ} \mathrm{C}, 100 \mu \mathrm{L}$ were spread on nutrient agar (NA) plates and incubated at $37^{\circ} \mathrm{C}$ for $24 \mathrm{~h}$. The number of grown colonies was measured and the inhibition ratios were calculated with the following equation:

$$
\text { Inhibition ratio }(\%)=\frac{C-E}{C} \times 100,
$$

where $C$ is the average number of the surviving cells of the control groups (zero chitosan concentration) and $E$ is the average number of the surviving cells of the chitosan concentrations used.

2.7. Correlation between Used Quantitative Methods. The comparative sensitivity of the TTC method was calculated in comparison with plate colony count method (as a standard method) as follow:

The colony number (for plate count) and formazan absorbance reading (for TTC) in control samples (chitosanfree) was designated as $100 \%$. The percentages of survival cell counts and formazan absorbance, after incubation for $3 \mathrm{~h}$ at $37^{\circ} \mathrm{C}$ in the presence of $0.1,0.2,0.3,0.4$, and $0.5 \%$ from chitosan, were calculated as proportions from control sample. Correlations between the two methods were calculated for each treatment as follows:

$$
\frac{\text { Relative Formazan absorbance }(\%)}{\text { Relative Colony count }(\%)} \times 100 \text {. }
$$

The General correlation mean was calculated as follows:

$$
\frac{\text { The sum of average correlation values }}{\text { No. of treatments }} \text {. }
$$

\section{Results}

3.1. Characterization of Produced Chitosan. The A. niger chitosan yield based on dry biomass was $27 \%$. The produced chitosan was characterized in terms of its quality; the physicochemical characteristics of produced chitosan were the weight color, viscosity of 3.2 centipoises, molecular weight of $2.4 \times 10^{4} \mathrm{Da}$, deacetylation degree of $89.2 \%$, and $96 \%$ solubility in $1 \%$ acetic acid solution without further heating or sonication.

\subsection{Antibacterial Activity of Chitosan}

3.2.1. Zone of Inhibition Test. The inhibition zone assay revealed primarily two types of observations, namely, discs without any surrounded clear or inhibition zones which could be attributed to the absence of any inhibitory activity and clear inhibition zone representing the bacteriostatic action of fungal chitosan. This method is the universal qualitative assay as shown in Figure 2. 


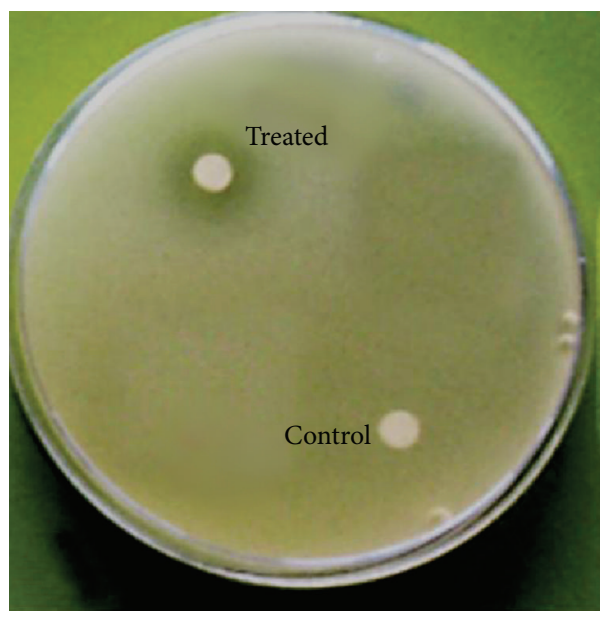

(a)

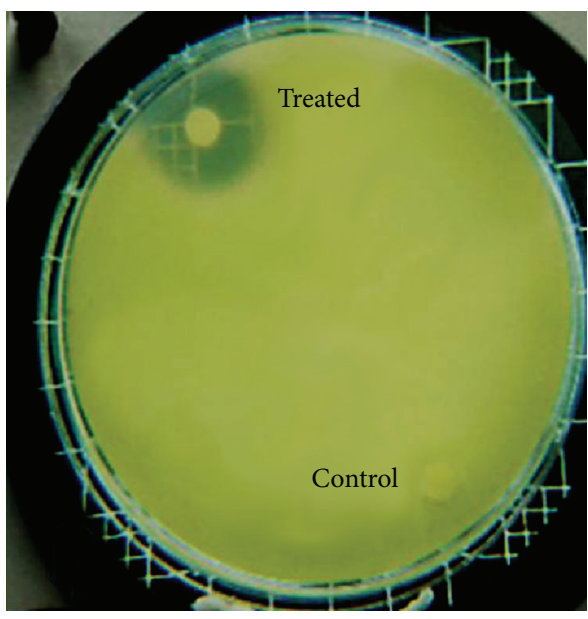

(b)

FIGURE 2: Zones of growth inhibition appeared after fungal chitosan treatments against (a) Salmonella typhimurium and (b) Staphylococcus aureus. Assay disc carried $20 \mu \mathrm{L}$ of $0.5 \%$ chitosan solution.

The examined chitosan exhibited prominent inhibitory effect against $S$. typhimurium and S. aureus as indicated by their clear zones. The diameter of inhibition zones, including paper disc diameter, were 16 and $24 \mathrm{~mm}$ for S. typhimurium and $S$. aureus, respectively.

3.2.2. Plate Count Agar. In total count agar method, chitosan showed a powerful antibacterial activity against the two examined strains. Chitosan was more effective against $S$. aureus compared to S. typhimurium. As shown in Figure 3, treatment with $0.5 \%$ from chitosan leads to $98.7 \%$ and $97.2 \%$ reduction in S. aureus and S. typhimurium growth, respectively, after the incubation for $5 \mathrm{~h}$.

3.2.3. Tetrazolium/Formazan Test Method (TTC Test). The antibacterial activity of chitosan with different concentrations, against the examined bacterial strains, was evaluated using 2,3,5-triphenyl-2H-tetrazolium chloride (TTC) reagent. Figures $4(\mathrm{a}), 4(\mathrm{~b})$, and 5 show the antibacterial activity, which was expressed by the formation of red formazan in Figure 4 and the formazan absorbance values in Figure 5, for the bacteria S. typhimurium and S. aureus treated with gradual chitosan concentrations. The results shown in Figures $4(\mathrm{a}), 4(\mathrm{~b})$, and 5 are with a strong agreement with the results shown before. A strong reduction of the vital cells due to the presence of chitosan could be observed. Increasing the concentration of chitosan in NB resulted in more potency of antibacterial activity as evidenced by lower red color intensity. The presence of more vital cells resulted in a heavy red color from the transformed formazan in growth media; the reduction in color intensity could be markedly observed with the prolongation of treatment with chitosan. The absorbance of formed formazan color at $480 \mathrm{~nm}$ (Figure 5) revealed that, after the first hour of incubation, the absorbance was 1.82 for S. aureus and 1.79 for S. typhimurium.

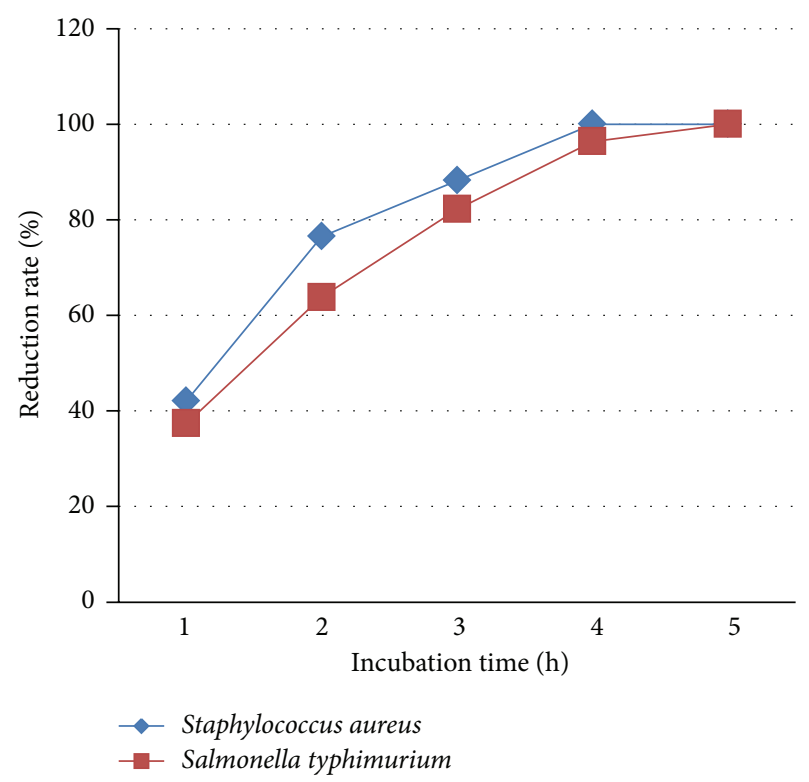

FIgURE 3: Reduction rate in Staphylococcus aureus and Salmonella typhimurium count after treatment with chitosan determined by plate count agar.

The absorbance continued to decrease down to zero after $4 \mathrm{~h}$, for S. typhimurium, and $5 \mathrm{~h}$, for S. aureus, from the incubation time with fungal chitosan.

\subsection{Comparability of TTC to Standard Quantitative Method.} The treated bacterial cells, with different chitosan concentrations, were subjected to plate count agar and TTC/formazan assay, as quantitative evaluating methods, and the correlation between methods' results was calculated (Table 1). High correlation averages were calculated between the two methods 
TABLE 1: The sensitivity of TTC method to determine the survival rate of treated bacterial strains with chitosan, compared to plate count method.

\begin{tabular}{|c|c|c|c|c|c|c|}
\hline \multirow{2}{*}{$\begin{array}{l}\text { Chitosan } \\
\text { conc. }(\%)\end{array}$} & \multicolumn{2}{|c|}{ S. typhimurium ${ }^{*}$} & \multirow{2}{*}{ Average correlation $\%$} & \multicolumn{2}{|c|}{ S. aureus ${ }^{*}$} & \multirow{2}{*}{ Average correlation \% } \\
\hline & $\begin{array}{l}\text { Relative colony } \\
\text { count }(\%)\end{array}$ & $\begin{array}{l}\text { Relative formazan } \\
\text { absorbance \% }\end{array}$ & & $\begin{array}{l}\text { Relative colony } \\
\text { count }(\%)\end{array}$ & $\begin{array}{l}\text { Relative formazan } \\
\text { absorbance \% }\end{array}$ & \\
\hline $\begin{array}{l}\text { Control } \\
(0)\end{array}$ & 100 & 100 & & 100 & 100 & \\
\hline 0.1 & 59.93 & 58.38 & 97.41 & 61.05 & 59.34 & 97.20 \\
\hline 0.2 & 26.85 & 27.22 & 101.38 & 29.93 & 28.78 & 96.16 \\
\hline 0.3 & 13.81 & 14.13 & 102.32 & 16.94 & 17.17 & 101.36 \\
\hline 0.4 & 1.92 & 1.89 & 98.44 & 6.41 & 6.56 & 102.34 \\
\hline \multirow[t]{2}{*}{0.5} & 0.42 & 0.40 & 95.24 & 2.81 & 2.91 & 103.56 \\
\hline & \multicolumn{2}{|c|}{ General correlation mean } & 98.96 & \multicolumn{2}{|c|}{ General correlation mean } & 100.12 \\
\hline
\end{tabular}

* Treated bacteria were incubated for $3 \mathrm{~h}$ at $37^{\circ} \mathrm{C}$ before testing.

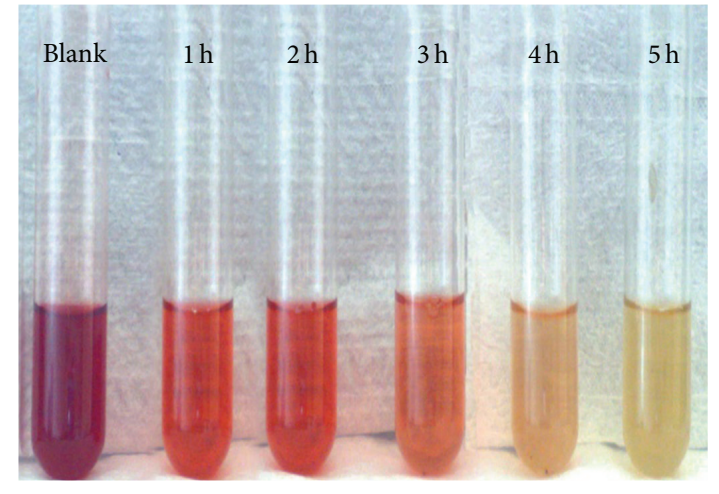

(a)

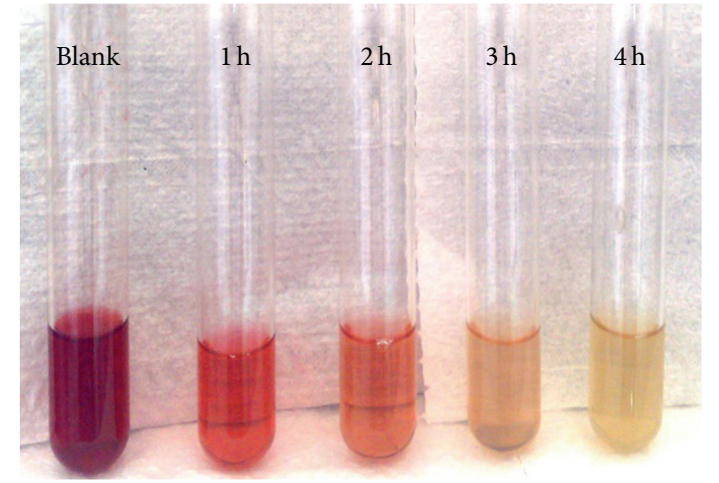

(b)

FIGURE 4: (a) TTC test method of $0.1 \%$ chitosan against $S$. typhimurium. (b) TTC test method of $0.1 \%$ chitosan against $S$. aureus.

results, regarding each individual treatment. The correlation was more proved in gram-positive strain (S. aureus) than in gram-negative (S. typhimurium), especially in the higher examined concentrations from chitosan. The correlation averages between plate count and TTC/formazan, as antibacterial evaluating methods, ranged from 95.24 to 102.32 for $S$. typhimurium and from 96.16 to 103.56 for S. aureus.

\section{Discussion}

The obtained results in this study indicated that the produced fungal chitosan had a powerful antibacterial activity against both gram-positive and gram negative strains. Regarding the biological activity of chitosan, the antibacterial activity of chitosan is a hot research topic and there are several articles that deal with it and its derivatives [1, 4, 18-20]. It has been tested as an additive to textiles $[2,3,6,7]$, and it was proved to have strong effects on various bacteria, yeast, and fungal species.

The application of TTC add an indicator for the antibacterial activity, in current study, proved to be an efficient evaluation method. Tetrazolium salts are a large group of organic

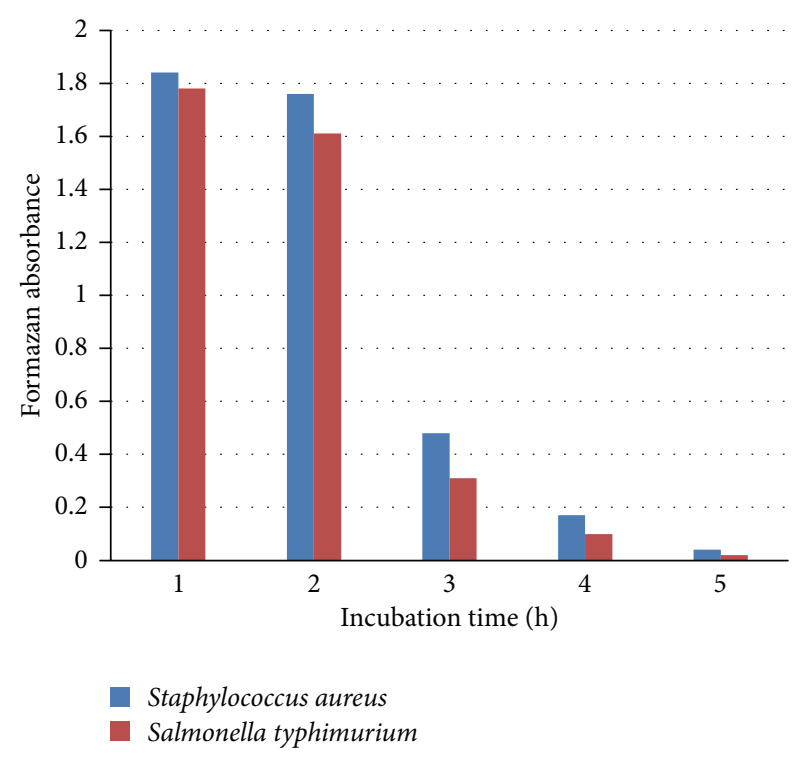

FIGURE 5: Determination of formed formazan, with absorbance at $480 \mathrm{~nm}$, after treatment of bacterial strains with chitosan for different incubation periods. 
compounds, with the first being prepared in 1894 [21-23]. Their most significant trait is their ability to form highly coloured products, known as formazans, upon reaction. This feature can be used to detect biological reducing systems [21, $22,24,25]$. The tetrazolium salts are nowadays widely used both in chemistry and biology $[21,26,27]$. The change in color of tetrazolium chloride (TTC), due to contact with live cells, may also be a useful technique for resolving uncertainties between hazy, bacteriostatic growth, or the accumulation of dead cells.

The tetrazolium salts that are most commonly used are stable, water-soluble solids, ranging in colour from white to various shades of yellow and brown. During mild reduction, the highly coloured formazans are produced $[22,28,29]$. The classical application for tetrazolium salts is in the histochemical demonstration of oxidative enzymes, most of which are straightforward reactions involving dehydrogenases and oxidases $[26,30]$.

The fact that chitosan likely has limited diffusion in agarbased assays relative to other antimicrobials might suggest that the proposed methodology could be useful in providing quantitative data for similarly non-diffusible materials.

Antibacterial activity of chitosan was determined using TTC as the artificial electron acceptor, which was changed from colorless to red triphenyl formazan (TPF) in the presence of living microorganisms. TTC method could be considered as a qualitative and quantitative antibacterial test method and also a quick method for evaluating the antibacterial activity of chitosan. The TTC test serves as an indicating system for the determination of the viability of bacterial cell, since absorbance of formazan, measured at $480 \mathrm{~nm}$, is directly proportional to the amount of living bacteria.

The higher inhibitory activity shown by chitosan can be attributable to the higher amount of positive surface charge which could make it more reactive against bacterial cells. The inhibitory effects of chitosan concentrations were remarkably higher for $S$. aureus than for S. typhimurium as indicated by the wider diameter of inhibition zones. The average correlation between relative formazan absorbance and relative colony count was more evidenced in $S$. aureus than in $S$. typhimurium, especially in the low values, and that may be attributed to the higher activity of gram-positive bacteria to reduce TTC into red formazan, compared to gram-negative strain. The values of average correlations between the two methods, during treatment periods, recommend the usage of YYC/formazan assay as a complement, or even alternative, to methods currently accepted for quantitative antibacterial evaluation.

In conclusion, the accuracy, shorter turnaround time, simple technique, and cost-effectiveness make the TTC colorimetric method a promising alternative for qualitative and quantitative method to determine the antibacterial activity of chitosan or other antibacterial agents. The simplicity of this method may make it possible for testing first-, second-, and third-line antibacterial agents on a routine basis, thereby allowing the rapid detection of bacterial isolates while at the same time providing valuable susceptibility data.

\section{References}

[1] H. Liu, Y. Du, X. Wang, and L. Sun, "Chitosan kills bacteria through cell membrane damage," International Journal of Food Microbiology, vol. 95, no. 2, pp. 147-155, 2004.

[2] A. A. Tayel, S. Moussa, K. Opwis, D. Knittel, E. Schollmeyer, and A. Nickisch-Hartfiel, "Inhibition of microbial pathogens by fungal chitosan," International Journal of Biological Macromolecules, vol. 47, no. 1, pp. 10-14, 2010.

[3] S. Moussa, A. Ibrahim, A. Okba, H. Hamza, K. Opwis, and E. Schollmeyer, "Antibacterial action of acetic acid soluble material isolated from Mucor rouxii and its application onto textile," International Journal of Biological Macromolecules, vol. 48, no. 5, pp. 736-741, 2011.

[4] E. I. Rabea, M. E. Badawy, C. V. Stevens, G. Smagghe, and W. Steurbaut, "Chitosan as antimicrobial agent: applications and mode of action," Biomacromolecules, vol. 4, no. 6, pp. 1457-1465, 2003.

[5] S. Lim and S. M. Hudson, "Review of chitosan and its derivatives as antimicrobial agents and their uses as textile chemicals," Journal of Macromolecular Science-Polymer Reviews, vol. 43, no. 2, pp. 223-269, 2003.

[6] A. A. Tayel, S. H. Moussa, W. F. El-Tras, N. M. Elguindy, and K. Opwis, "Antimicrobial textile treated with chitosan from Aspergillus niger mycelial waste," International Journal of Biological Macromolecules, vol. 49, no. 2, pp. 241-245, 2011.

[7] A. A. Tayel, S. Moussa, W. F. El-Tras, D. Knittel, K. Opwis, and E. Schollmeyer, "Anticandidal action of fungal chitosan against Candida albicans," International Journal of Biological Macromolecules, vol. 47, no. 4, pp. 454-457, 2010.

[8] Y. Li, X. G. Chen, N. Liu et al., "Physicochemical characterization and antibacterial property of chitosan acetates," Carbohydrate Polymers, vol. 67, no. 2, pp. 227-232, 2007.

[9] M. Kong, X. G. Chen, K. Xing, and H. J. Park, "Antimicrobial properties of chitosan and mode of action: a state of the art review," International Journal of Food Microbiology, vol. 144, no. 1, pp. 51-63, 2010.

[10] J. H. Jorgensen, J. D. Turnidge, and J. A. Washington, "Antibacterial susceptibility tests: dilution and disk diffusion methods," in Manual of Clinical Microbiology, pp. 1526-1543, ASM Press, Washington, DC, USA, 7th edition, 1999.

[11] C. Valgas, S. M. De Souza, E. F. A. Smânia, and A. Smânia Jr., "Screening methods to determine antibacterial activity of natural products," Brazilian Journal of Microbiology, vol. 38, no. 2, pp. 369-380, 2007.

[12] H. M. Wehr and J. H. Frank, Standard Methods for the Microbiological Examination of Dairy Products, APHA Inc., Washington, DC, USA, 17th edition, 2004.

[13] A. D. Eaton, L. S. Clesceri, A. E. Greenberg et al., Standard Methods for the Examination of Water and Wastewater, APHA, Washington, DC, USA, 21st edition, 2005.

[14] H. Barreteau, L. Mandoukou, I. Adt, I. Gaillard, B. Courtois, and J. Courtois, "A rapid method for determining the antimicrobial activity of novel natural molecules," Journal of Food Protection, vol. 67, no. 9, pp. 1961-1964, 2004.

[15] A. Sundsfjord, G. S. Simonsen, B. C. Haldorsen et al., "Genetic methods for detection of antimicrobial resistance," APMIS, vol. 112, no. 11-12, pp. 815-837, 2004.

[16] AOAC, Official Methods of Analysis of the Association of Official Analytical Chemists, Association of Official Analytical Chemists, Arlington, Va, USA, 15th edition, 1990. 
[17] D. H. Davies and E. R. Hayes, "Determination of the degree of acetylation of chitin and chitosan," Methods in Enzymology, vol. 161, no. C, pp. 442-446, 1988.

[18] Y. Chung, H. Wang, Y. Chen, and S. Li, "Effect of abiotic factors on the antibacterial activity of chitosan against waterborne pathogens," Bioresource Technology, vol. 88, no. 3, pp. 179-184, 2003.

[19] S. Chatterjee, M. Adhya, A. K. Guha, and B. P. Chatterjee, "Chitosan from Mucor rouxii: production and physico-chemical characterization," Process Biochemistry, vol. 40, no. 1, pp. 395400, 2005.

[20] J. Je and S. Kim, "Chitosan derivatives killed bacteria by disrupting the outer and inner membrane," Journal of Agricultural and Food Chemistry, vol. 54, no. 18, pp. 6629-6633, 2006.

[21] J. N. Eloff, "A sensitive and quick microplate method to determine the minimal inhibitory concentration of plant extracts for bacteria," Planta Medica, vol. 64, no. 8, pp. 711-713, 1998.

[22] L. Caviedes, J. Delgado, and R. H. Gilman, "Tetrazolium microplate assay as a rapid and inexpensive colorimetric method for determination of antibiotic susceptibility of Mycobacterium tuberculosis," Journal of Clinical Microbiology, vol. 40, no. 5, pp. 1873-1874, 2002.

[23] G. Abate, A. Aseffa, A. Selassie et al., "Direct colorimetric assay for rapid detection of rifampin-resistant Mycobacterium tuberculo]sis," Journal of Clinical Microbiology, vol. 42, no. 2, pp. 871873, 2004.

[24] F. P. Altman, "Tetrazolium salts and formazans," Progress in Histochemistry and Cytochemistry, vol. 9, no. 3, pp. 1-56, 1976.

[25] S. M. Thom, R. W. Horobin, E. Seidler, and M. R. Barer, "Factors affecting the selection and use of tetrazolium salts as cytochemical indicators of microbial viability and activity," Journal of Applied Bacteriology, vol. 74, no. 4, pp. 433-443, 1993.

[26] E. I. Kvasnikov, L. N. Gerasimenko, and Zh. Tabarovskaia, "Use of 2, 3, 5-triphenyl tetrazolium chloride for rapid detection of mesophilic anaerobic bacteria in the canning industry," Voprosy Pitaniia, no. 6, pp. 62-65, 1974.

[27] N. Yamane, T. Oiwa, T. Kiyota et al., "Multicenter evaluation of a colorimetric microplate antimycobacterial susceptibility test: comparative study with the NCCLS M24-P," Rinsho Byori, vol. 44, no. 5, pp. 456-464, 1996.

[28] R. N. Mshana, G. Tadesse, G. Abate, and H. Miörner, "Use of 3-(4,5-dimethylthiazol-2-yl)-2,5-diphenyl tetrazolium bromide for rapid detection of rifampin-resistant: Mycobacterium tuberculosis," Journal of Clinical Microbiology, vol. 36, no. 5, pp. 12141219, 1998.

[29] S. Lee, D. H. Kong, S. H. Yun et al., "Evaluation of a modified antimycobacterial susceptibility test using Middlebrook 7H10 agar containing 2,3-diphenyl-5-thienyl-(2)-tetrazolium chloride," Journal of Microbiological Methods, vol. 66, no. 3, pp. 548551, 2006.

[30] D. M. Yajko, J. J. Madej, M. V. Lancaster et al., "Colorimetric method for determining MICs of antimicrobial agents for Mycobacterium tuberculosis," Journal of Clinical Microbiology, vol. 33, no. 9, pp. 2324-2327, 1995. 

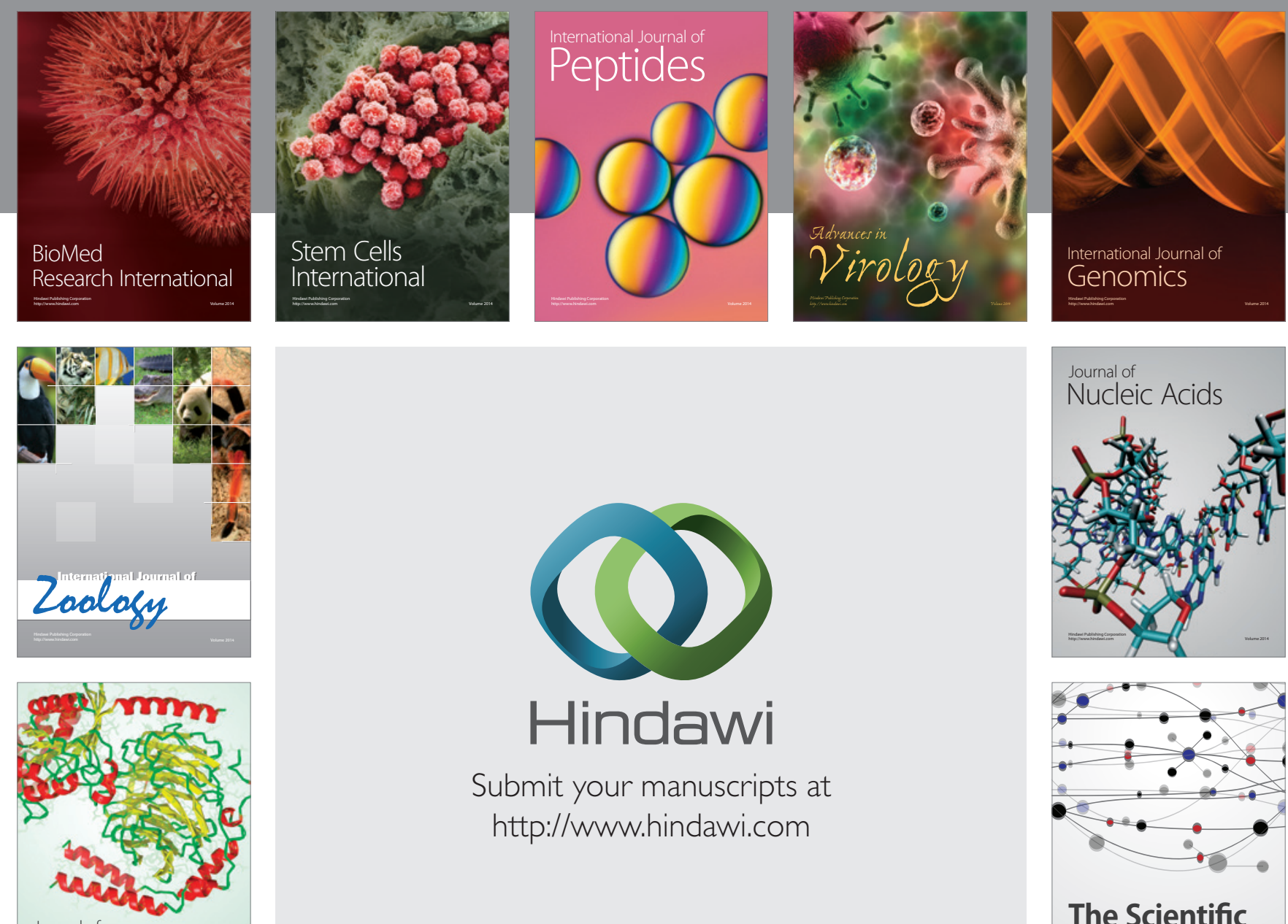

Submit your manuscripts at

http://www.hindawi.com

Journal of
Signal Transduction
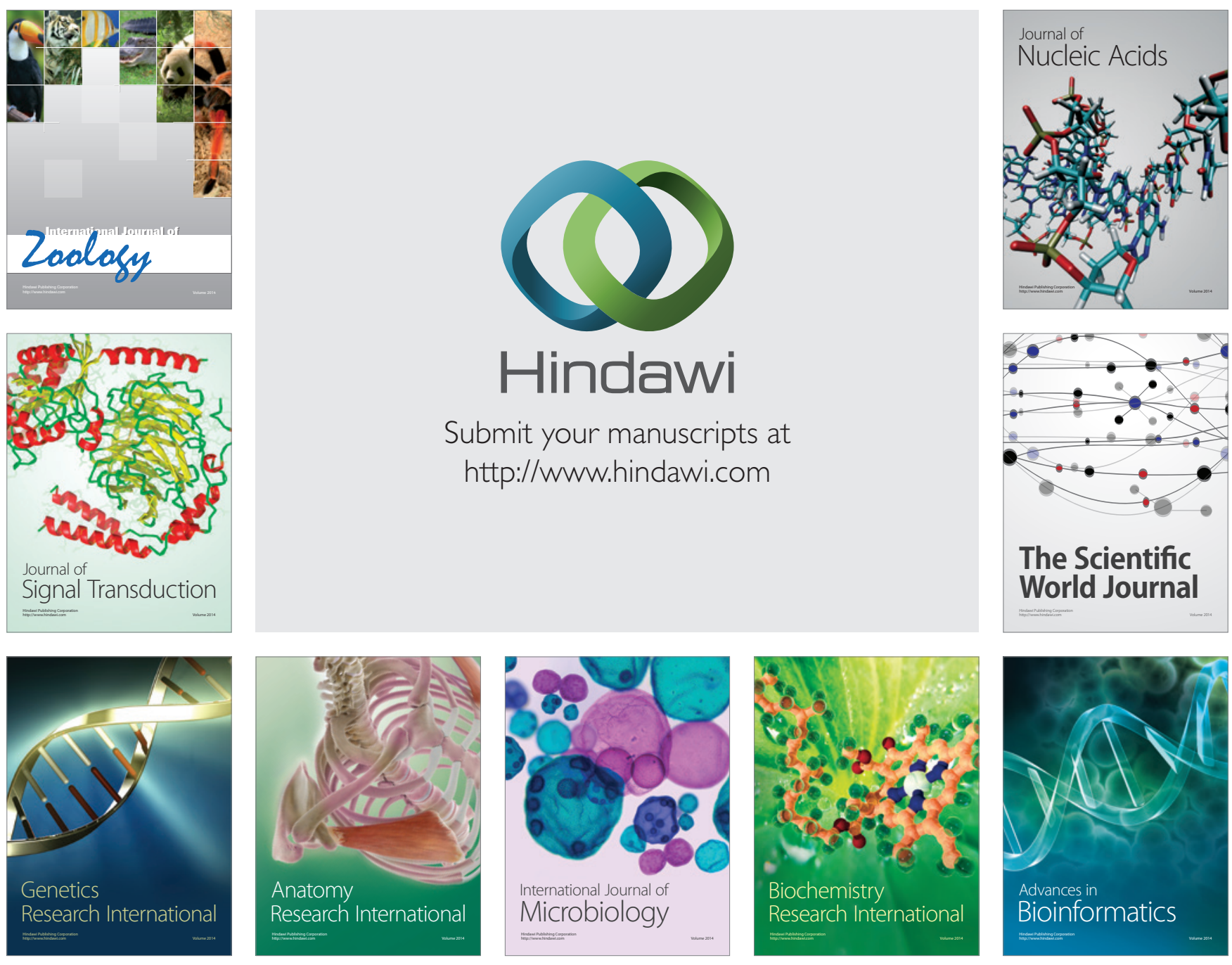

The Scientific World Journal
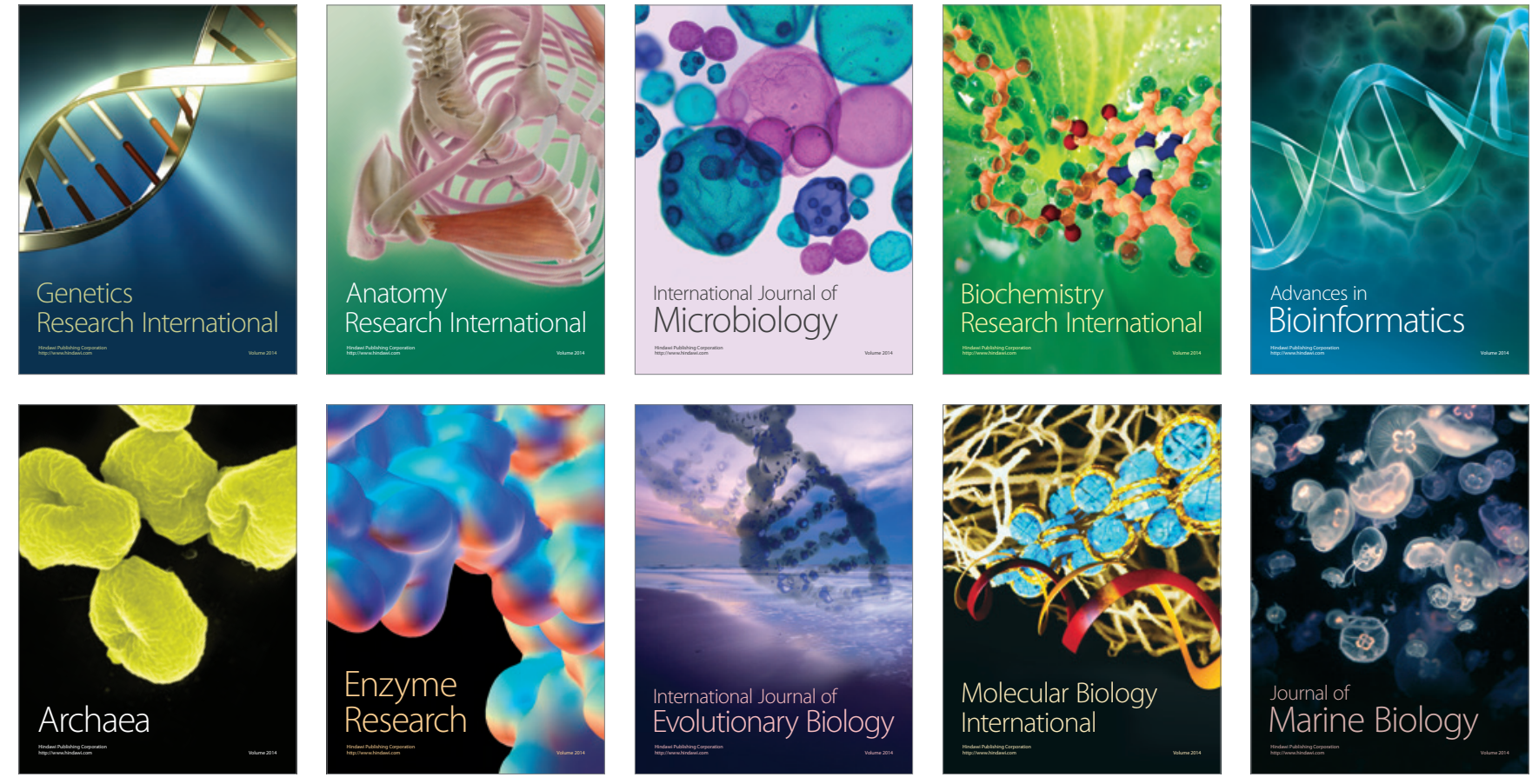